\title{
Constructing Incrementally Reinforced Excel Project Sets Using The S.M.A.R.T. Management Goal-Setting Approach
}

Gary Bronson, PhD, Fairleigh Dickinson University, USA Mel Stern, MS, Fairleigh Dickinson University, USA

\begin{abstract}
Sets of incrementally reinforced EXCEL spreadsheet cases have been constructed and used at Fairleigh Dickinson University over the past two years with a high degree of student involvement and participation. The construction of these cases is based on an adaptation of a management goal-setting technique, having the acronym S.M.A.R.T. This paper describes the application of this management goal-setting technique to the construction of spreadsheet case, and presents an example case illustrating its actual use.
\end{abstract}

Keywords: Spreadsheet skill set; case studies; student competencies; incrementally reinforced projects; innovation; goal-setting

\section{INTRODUCTION}

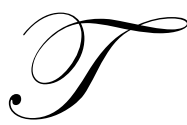

he importance of spreadsheets and Excel in both for-profit and non-profit institutions has been well documented. Spreadsheet competency was rated as the most important IT competency subject in a detailed survey of 111 employers of Northeastern University undergraduate business school students (Kesner, 2008). In responses from surveyed employers (Bartholomew, 2004), spreadsheet skills are seen as the most critical skills for business graduates, while Grossman, Mehrotra, and Özlük (2007) find that spreadsheets play a central role in the evolution of business processes and are widely used for mission-critical functions. Additionally, spreadsheet software, such as Excel, has been found to be a popular tool for data management in non-profit organizations (West and Green, 2008).

Gorgone et al. (2006) discussed that spreadsheet skills are covered in undergraduate IS programs and students are expected to possess these skills prior to entering the graduate degree programs in information systems. According to Aytes (2004), spreadsheets are usually covered in the first semester IS course in business curriculum. Neely (2004) discussed the fact that spreadsheet skills are increasingly being required both in Management Information Systems (MIS) programs and in Colleges of Business. A perusal of the syllabi on the ISWorld site (http://www.magal.com/iswn/teaching/intromis) indicates that these skills are frequently taught in introductory MIS courses. Other schools teach these skills in a dedicated applications course. Such courses are either designed as 3-4 credit courses where all Office applications are presented, including an introduction to the Internet, or, in many cases, as 1 or 2 credit courses that teach a smaller subset of these applications."

For this type of course to be effective and provide the benefits of active, learner-centered instruction, it is essential that a human be actively engaged with the students (Alphonce, 2003). This engagement includes providing help, encouragement, and praise to ensure students that they are on the correct learning path, and equally important, to ensure that the students are actually using the systems provided. This human instruction and interaction typically involves either meeting with the students on a pre-determined schedule, keeping in touch via email or electronicblackboard, or equivalent internet-based options. 


\section{THE STUDENT MIX}

The mix of students, learning styles, and competence can vary greatly across introductory IS classes. Nowhere is this more evident when applied to introductory IS and computer literacy classes.

Competency: Many students enter with little or no real understanding of basic spreadsheet techniques, while others possess a solid foundation. In many cases, those students who possess experience using spreadsheets tend to overestimate their own knowledge of the subject.

Learning Styles: Some students prefer to work alone, while others prefer group and collaborative projects. While some students flourish in a networked classroom setting, others prefer working at home with their own laptop computers.

Scheduling: Many students have work schedules that conflict with educational demands. For this group of students, web-based or hybrid courses are preferable.

Application Knowledge: Few students have, or can easily apply, the concepts they do know to even the most basic real-world applications (e.g. profit and loss, earned interest, mortgage payments, break-even points, budgeting, cash flow, etc.)

To provide the benefits of lecture-based courses while still realizing the benefits of self-paced, individualized instruction that Web-based courses provide, we have developed an approach to constructing sets of incrementally reinforced spreadsheet cases (Bronson, 2009). This approach is based on adapting the management goal-setting approach known as S.M.A.R.T. (Schwalbe, 2009), to the creation of Excel spreadsheet cases.

\section{CASE STUDY DEVELOPMENT USING S.M.A.R.T. GOALS}

The S.M.A.R.T. goal-setting technique, as applied to creating Excel spreadsheet cases, requires that all cases conform to the following criteria:

Specific learning objectives

Measureable results

Achievable results

Real-world applications

Time-based

As used at Fairleigh Dickinson University in our introductory IT course, the implementation of this methodology consisted of creating sets of reinforcing spreadsheet case studies that build within and among themselves (Bronson, 2009). Specifically, each set of S.M.A.R.T. projects consists of sets of related cases that reinforce a basic introductory concept using a real-world application. Table 1 indicates the current distribution of these cases.

Table 1: Topic Designations

\begin{tabular}{|l|c|c|}
\hline \multicolumn{1}{|c|}{ Learning Objectives } & Set & No. of Cases \\
\hline Data Types, Formulas, and Absolute Addressing, Input Data Sections & I & 6 \\
\hline Conditional Expressions & II & 3 \\
\hline VLOOKUP and HLOOKUP & III & 4 \\
\hline Cash Flow Applications & IV & 5 \\
\hline Graphing & V & 2 \\
\hline Database Sort & VI & \\
\cline { 1 - 2 } Database Search & & \\
\cline { 1 - 3 } Database Functions & & \\
\hline
\end{tabular}




\section{CASE OBJECTIVES}

The objective of each case, by itself, is thus not only to present a specific learning objective (1st S.M.A.R.T. criteria), but introduce it in a manner that also uses a real-world application (4th S.M.A.R.T. criteria) To be included in a set, a case must produce a measurable result (2nd S.M.A.R.T. criteria) and be achievable (3rd S.M.A.R.T. criteria) with just the information provided by the case. Finally, the compactness of each case makes it time-based, in that the solution must be handed in within a set time frame (5th S.M.A.R.T. criteria). The completion date is set to permit students to work on the projects either during class lab times or at home.

Within each set, the cases become progressively more difficult, where the earlier cases are used to first introduce one or more basic concepts, and later cases then incrementally reinforce and advance the concept under consideration. Regardless of the topic, however, all of the cases, independent of the set they are contained within, must present either a basic or more advanced technique, within the context of a real-life application.

\section{An Example}

To illustrate how a case study set is constructed in practice, we present the first case in Set I and how it is used in our basic computer literacy course. Each case is presented within a broader framework that consists of preceding each case with information related to the topic under consideration, provided either as a lecture or with reference notes. The student is then asked to work on the case, followed by a post-analysis that can be carried out in class or via the Internet. Students are free to work ahead of the class by starting a case at any time they desire.

\section{Case 1}

\section{Learning Objectives}

The basics of a spreadsheet, how to navigate between cells, how to enter data, and most importantly, the distinction between a numerical entry, a text entry, and a formula entry.

\section{The Case}

This first case is to design and develop a worksheet which calculates the charges along with the servicing fee for private duty nursing services in a practical environment, such as a hospital. Such services are requested by patients for either (or all) a day shift, an evening shift, or a night shift. In addition, the patient may request a Registered Nurse (RN), a Licensed Practical Nurse (LPN), or an aide. The charges for such services are paid directly to the agency that provides the private duty nurses. This application appears to be rather simple and trivial, and the majority of students regard it in this manner. At a most basic level, however, it does include all of the learning objectives for Set I that are listed in Table 1 and that will be expanded upon in the subsequent cases in the first set, except for the introduction of a clearly defined input section. The case requires students to enter a variety of data types and create simple addition and multiplication formulas to complete the spreadsheet (see Figure 1).

\begin{tabular}{|c|c|c|c|c|c|c|c|c|}
\hline \multirow[t]{2}{*}{ Profit: } & \multicolumn{2}{|l|}{$7 \%$} & & & & & & \\
\hline & & & \multicolumn{2}{|c|}{ First Shift } & \multicolumn{2}{|c|}{ Second Shift } & \multicolumn{2}{|c|}{ Third Shift } \\
\hline Designation & Nursing & Cost & Hired & Cost & Hired & Cost & Hired & Cost \\
\hline RN & $\$ 400.00$ & /shift & 2 & & 3 & & 6 & \\
\hline LPN & $\$ 310.00$ & /shift & 4 & & 8 & & 9 & \\
\hline \multirow[t]{3}{*}{ Aide } & $\$ 200.00$ & /shift & 0 & & 4 & & 8 & \\
\hline & \multicolumn{2}{|c|}{ Total Cost } & & & & & & \\
\hline & & Profit & & & & & & \\
\hline \multicolumn{3}{|c|}{ Charge for Service } & & & & & & \\
\hline
\end{tabular}

Figure 1: Case 1's Spreadsheet

As you will recall, the purpose of each case is to introduce and/or reinforce a designated topic. Additionally, when possible, a case will provide at least one subtle feature, which we refer to as a "gotcha" (or "trap"). Here is how this is accomplished in Case 1: 
What the Case Introduces: It shows how to enter data and create formulas, and being aware of various data types.

What the Case Reinforces: It provides students with a spreadsheet that can be completed relatively quickly, providing a feeling of success, and some confidence in entering data and creating a simple multiplication and addition formula.

The "Gotcha" or "Trap": The "gotcha" in this case is specifically meant to reveal to students that they may have taken data types a bit too lightly and really must pay attention to what is being entered into a cell. This occurs when the students fail to specifically realize that the /shift entries are text, and must be entered as such, and not be entered within the cell containing the actual shift rate.

Knowledge Enhancements: Three important elements of knowledge that students typically are not aware of, and that we use as the basis for a post-analysis are:

1. The $\operatorname{SUM}()$ function can be used to conveniently add numerical data.

2. By using a literal value of either 0.07 or $7 \%$ in computing the profit, they run the risk of forgetting to make the change to three places if the profit margin changes. What really should be used, at a minimum, is an address that references the value in cell B2. This leads into the topic of absolute addresses.

3. Some students, usually those with a little experience using Excel, will want to know how to create either a line or underline data in a cell, as shown in Figure 1. Many students will fail to even notice the line, let alone think of creating one.

These more subtle points to spreadsheet development begin the process of alerting students to the fact there may be considerably more than what immediately meets the eye when preparing a worksheet. Typically, the most "eye-opening" feature to many students is the usefulness of copying a formula rather than continually entering it. Finally, the spreadsheet gives students an immediate boost of confidence that, although they may have missed a few points, they can successfully complete a worksheet and print it out. Figure 2 shows some of the points raised by the first case, as enumerated above.

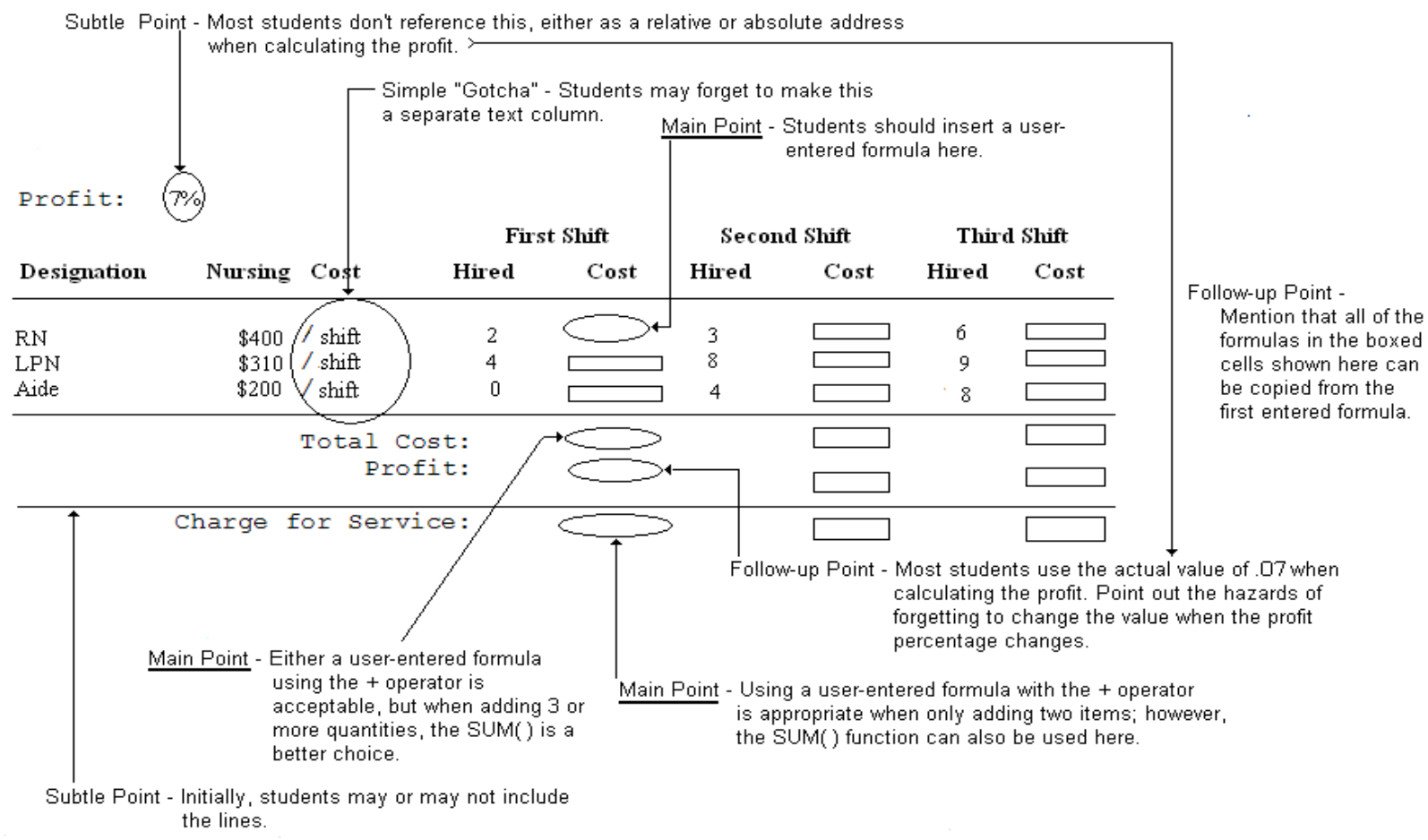

Figure 2: The Various Points Illustrated in Case 1 
Finally, for reference purposes, the spreadsheet shown in Figure 3 is handed out so that the student has a record of how an experienced user would create the spreadsheet and how easily it can be constructed by copying formulas rather than entering each one manually.

\begin{tabular}{|c|c|c|c|c|c|c|c|c|c|}
\hline \multirow[b]{2}{*}{1} & A & B & C & D & $E$ & $\mathrm{~F}$ & G & \multicolumn{2}{|l|}{ H } \\
\hline & & & & & & & & & \\
\hline 2 & \multirow[t]{2}{*}{ Profit: } & $7 \%$ & & & & & & & \\
\hline 3 & & & & \multicolumn{2}{|c|}{ First Shift } & \multicolumn{2}{|c|}{ Second Shift } & \multicolumn{2}{|c|}{ Third Shift } \\
\hline 4 & Designation & Nursing & Cost & Hired & Cost & Hired & Cost & Hired & Cost \\
\hline 5 & $\mathrm{RN}$ & $\$ 400$ & /shift & 2 & $=\mathrm{B} 55^{*} \mathrm{D} 5$ & 3 & $=\mathrm{B} 5^{*} \mathrm{~F} 5$ & 6 & $=\mathrm{B} 55^{*} \mathrm{H} 5$ \\
\hline 6 & LPN & $\$ 310$ & /shift & 4 & & 8 & & 9 & \\
\hline 7 & Aide & $\$ 200$ & /shift & 0 & $\downarrow$ & 4 & $\downarrow$ & 8 & $\downarrow$ \\
\hline 8 & & Tota & al Cost: & & $=S U M(E 5: E$ & & $\Rightarrow$ & & $\rightarrow$ \\
\hline 9 & & & Profit: & & $=\$ B \$ 22^{*} \mathrm{E} 8$ & & $\rightarrow$ & & $\rightarrow$ \\
\hline 10 & & harge for 5 & Service: & & $=\mathrm{E} 8+\mathrm{Eg}$ & & $\Rightarrow$ & & $\rightarrow$ \\
\hline
\end{tabular}

Figure 3: How Case 1 should be Completed

Each case in Set 1 (as in all the other sets) is created and is presented in this same manner. Specifically, the purpose of the second case is to provide reinforcement of the lessons learned from the first spreadsheet, while incrementally adding the new task requirement that students must create their own formulas and headings. The one question that it forces students to ask is "How do I get Excel to display and print headings on two lines?" This brings up the necessity of exploring text formatting using the word-wrap option. In selecting this option, the students have their first look at a dialog box that is used later to merge and unmerge cells. In addition, the necessity of using absolute addresses is now directly addressed as a requirement in the case.

Finally, in the post-analysis, it is pointed out that many have still missed the importance of understanding the difference between text and numerical data. In this second case this manifests itself by a missing leading zero in two identification numbers. This is intended to instill upon the student the need to really look at what they are presenting and to reinforce the distinction between numbers and text. Only those entities that can be mathematically manipulated using addition, subtraction, multiplication, or division should be formatted as numbers; while entities such as identification numbers and zip codes, although they appear as numbers, should be formatted as text, precisely to avoid a leading zero error.

It is using this approach, a carefully constructed and thought-provoking learning process continues incrementally and through trial and error. An important part of this process is discovering what does not work within the context of a basically successful case, and discovering both what one knows and what one does not know, so that the information can fit into a unified whole.

\section{SUMMARY}

In order to test the effectiveness of each case, the complete set of cases was used in 15 sections of the initial undergraduate MIS courses during the time period Fall 2006 through Fall 2009. The focus in this course is to develop a solid foundation of the basic principles and commands/techniques associated with basic to intermediate Excel skill sets.

Each learning "module" was presented to students as a lecture and demonstration session. Following a general introduction and demonstration on a specific learning objective, the cases were assigned in sequence and used in the place of the exercises found at the end of traditional Excel hands-on oriented textbooks.

Although we were extremely gratified by the overall increase in student attendance, engagement with the projects, and the high degree of student interaction with each other and the instructor, we are still in the early stages of testing the effectiveness of the cases as a whole. Specifically, the learning environment has been observed to be 
much more engaging than the traditional classroom/lab setting. The immediate feedback, on a project-by-project basis, appears to help keep the students more interested, and the positive reinforcement within each project that provides consistent "wins," helps to continue to increase a student's sense of competency. These, however, are all qualitative results.

At present, having finalized the projects and their distribution among sets, we are gathering data on case completion times and accuracy scores to statistically determine quantitative metrics to compare classes taught by the same professor, classes taught using in-class labs and lecture classes, and across various classroom settings.

\section{AUTHOR INFORMATION}

Gary Bronson has been a professor of Information Systems at Fairleigh Dickinson University since 1980. During the past 10 years he has twice been awarded Teacher of the Year, once at the college level and once at the campus level. In 2007 he was awarded the University's award for outstanding research and publication, having authored over fifteen textbooks on programming languages. These include Visual Basic, C, C++, and Java. He has also been a consultant for a number of Wall Street financial firms and was an invited lecturer to Bell Laboratories' in-house continuing education program.

Mel Stern is a Lecturer at the Silber man College of Business, Fairleigh Dickinson University. He teaches graduate and undergraduate courses in Management Information Systems and Operations Management. His previous business experience has been in the pharmaceutical, neutraceutical and personal care industries. His research interests include IS education, Internet applications for manufacturing systems and mass customization. In addition to his appointment at Fairleigh Dickinson University, he is an adjunct professor at Stevens Institute of Technology. He received an M.S. in Industrial Engineering from New York University.

\section{REFERENCES}

1. Alphonce, C. (2003) 'Computer Literacy', National Center for Academic Transformation. Available at http://www.center.rpi.edu/

2. Aytes, K. (2004) 'Adding Value to the Core Business Curriculum: Innovative Use of IS Courses'. Americas Conference on Information Systems 2004 Proceedings. Available at: http://aisel.aisnet.org/amcis2004/25

3. Bartholomew, K. W. (2004) 'Computer literacy: is the emperor still exposed after all these years?', Journal of Computing Sciences in Colleges, Vol. 20, Issue 1, October 2004.

4. Bronson, G., Qin, L., Hsu, J., 'Teaching Excel using Incrementally Reinforced Project Sets' International Journal of Innovation and Learning, accepted and to be published in 2009-2010.

5. Gorgone, J. T., Gray, P., Stohr, E. A., Valacich, J. S., and Wigand, R. T. (2006) 'MSIS 2006: Model Curriculum and Guidelines for Graduate Degree Programs in Information Systems', Communications of the Association for Information Systems, Vol. 17, Article 1. Available at: http://aisel.aisnet.org/cais/vol17/iss1/1

6. Grossman, T. A., Mehrotra, V. and Özlük, Ö. (2007) 'Lessons from Mission-Critical Spreadsheets', Communications of the Association for Information Systems, Vol. 20, Article 60. Available at: http://aisel.aisnet.org/cais/vol20/iss1/60

7. Kesner, R. M. (2008) 'Business School Undergraduate Information Management Competencies: A Study of Employer Expectations and Associated Curricular Recommendations', Communications of the Association for Information Systems, Vol. 23. Available at: http://aisel.aisnet.org/cais/vol23/iss1/35

8. Neely, M. P. (2004) 'A Case Based Approach to Teaching Spreadsheet and Database Applications'. Americas Conference on Information Systems 2004 Proceedings. Available at: http://aisel.aisnet.org/amcis2004/367

9. West, H. and Green, G. (2008) 'Because Excel will Mind Me! The State of Constituent Data Management in Small Nonprofit Organizations'. Americas Conference on Information Systems 2008 Proceedings. Available at: http://aisel.aisnet.org/amcis2008/336 